\title{
ACUTE SUPPURATIVE ARTHRITIS IN INFANCY AND CHILDHOOD
}

\author{
Dennis C. Paterson, Adelaide, Australia \\ From the Department of Orthopaedic Surgery, Adelaide Children's Hospital
}

In 1935 Inge and Liebolt pointed out that the attitude of the medical profession towards acute suppurative arthritis in infancy had been a singularly variable one. There had always been respect for it, but the forms of treatment advocated had been many and the principles underlying them often diametrically opposed. There has long been controversy between those favouring incision and drainage of infected joints and those who favour aspiration and treatment with specific antibiotics.

In general it may be said that the chief concern of seventeenth- and eighteenth-century surgeons in such cases was to preserve the life of the patient, and there was a leaning towards amputation of the limb. In the nineteenth century surgeons tried, in addition, to save the affected limb even though it became ankylosed. With the beginning of the twentieth century came the idea of preserving the function of infected joints rather than encouraging ankylosis. Treatments advocated have included incision of the joint, repeated aspiration, complete rest and immobilisation, and disinfection of the joint with chemical or biological products; the question whether or not drainage tubes should be used after incision has remained controversial.

By the 1950's most writers believed that early diagnosis should be made and early arthrotomy performed, and that destruction of cartilage was more likely thus to be obviated than it was under treatment by repeated aspiration. Early arthrotomy has not, however, been widely practised, and in consequence the late effects of acute suppurative arthritis in infants and children are still seen today despite the wide use of antibiotics for the control of local and systemic infection. The literature contains, in the main, opinions based upon theory, and there is a surprising paucity of accurate clinical review.

Dissatisfied with the results of treatment by aspiration, drainage or antibiotics, orthopaedic surgeons at the Adelaide Children's Hospital have since 1960 treated these patients according to a strict routine, none of which is new, but which is simply a combination of accepted methods. The method is based on four main principles and it is considered that anything short of the full routine is inadequate.

\section{DETAIIS OF TREATMENT}

Immediate arthrotomy-Every hour that an acute suppurative process continues within a joint is of urgent significance to prognosis, and in the cases under review patients have been operated upon as an emergency. At operation the capsule and synovium of the joint have been opened by a cruciate incision and parts of each excised to ensure continued decompression. In the case of the hip joint-which is by far the commonest joint affected-a posterior musclesplitting incision has proved to be simple and adequate. Relief of tension is one of the essential factors in management because it allows capsular blood flow to return with its contained antibiotics and prevents the necrosis so typical of Tom Smith's arthritis of infancy. There is evidence that the staphylococcus produces an enzyme that destroys the matrix of articular cartilage and this, together with the intra-articular pressure, is a potent cause of destruction of the articular cartilage. Before skin closure, one million units of aqueous penicillin have been instilled because penicillin in high enough concentration will control most so-called penicillin resistant organisms. 
Complete skin closure without drainage-The problem of secondary infection is at least as significant in an already infected joint as in an aseptic operation, such as removal of a semilunar cartilage. Why then should we drain infected joints provided it can be shown that the existing infection can be adequately overcome without a drain? There is usually one causal organism sensitive to one of the antibiotics, and we should try to keep it that way until the infection is overcome.

Fifty joints treated by this routine, in which treatment was begun within five days of onset, have all shown primary wound healing, and furthermore all are clinically and radiologically normal to date.

Immobilisation-A plaster shoulder or hip spica or limb plaster has been applied for six weeks to provide immobilisation of the affected joint. There has been no evidence of residual stiffness.

At some centres traction is commonly used to help rest acutely infected joints. It aims also to overcome muscle spasm and pain, and to relieve pressure within the joints. These effects can be produced much more rapidly by immediate arthrotomy and immobilisation. It is suggested that traction has little place in the treatment of suppurative arthritis and it delays a decision to perform arthrotomy.

Antibiotics-Antibiotics are used for six weeks. This long period is recommended because there is evidence that osteomyelitis does better with such a period of continuous antibiotic cover, and many cases of suppurative arthritis begin as primary osteomyelitis, especially in the hip. Immediately after arthrotomy, intramuscular aqueous penicillin in maximal dosage is used until sensitivity tests of the cultured aspirate indicate the appropriate broad-spectrum antibiotic, usually erythromycin.

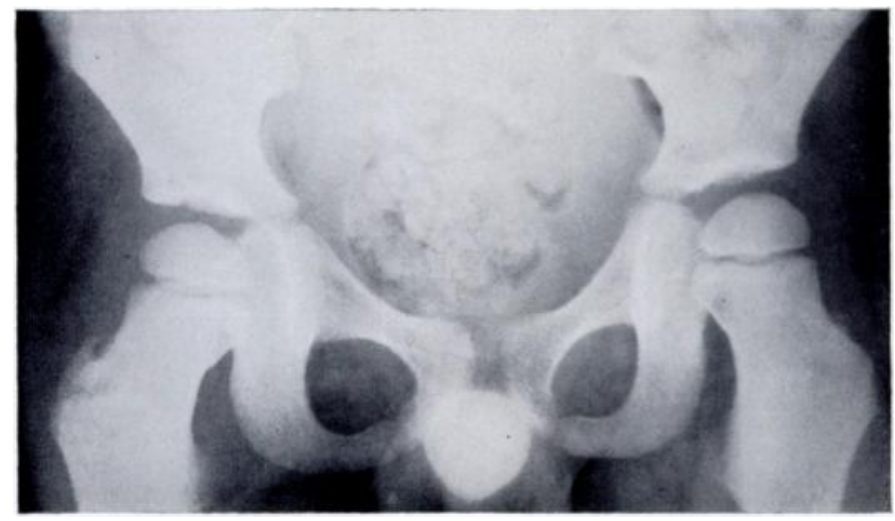

FiG. 1

Antero-posterior radiograph of a hip joint showing capsular distension.

\section{ASPIRATION OF JOINTS}

Samilson, Bersani and Watkins (1958), Eyre-Brook (1960), McFarland (1961), Wainwright (1961) and others, have advocated drainage of the affected joint, yet many of them are prepared to accept aspiration as the method of choice.

In superficial joints aspiration and antibiotic replacement is easy and there is no doubt that good results can be obtained. However, it does have certain drawbacks. The choice of antibiotics is limited and most broad-spectrum ones are irritants. In superficial joints it has the objection that tension will recur; repeated aspiration is painful and in children requires general anaesthesia. More particularly, this review has shown that the results of this method are most uncertain.

For deep joints aspiration can be most misleading for diagnosis. Time and again, with a bulging hip joint capsule exposed it has been impossible to aspirate pus through a large

VOL. 52 B, No. 3, AUGUST 1970 
needle, and yet pus, under considerable tension and sometimes spurting a foot or more, has been obtained on opening the joint. It is suggested that aspiration has no place in the treatment of suppurative arthritis of the hip, and it is not considered a safe method for any other joint.

\section{DIAGNOSIS}

Early diagnosis is the key to successful treatment at all ages, and especially so in the newborn. Suppurative arthritis should be suspected in patients who have a sudden onset of restriction of joint movement, particularly rotation, together with muscle spasm. This is especially so in newborn babies, in whom there may be minimal evidence of infection.

Leucocytosis with a shift towards immature cells, together with pyrexia and raised blood sedimentation rate, provides useful supporting evidence.

An important radiological sign-A most helpful radiological sign is capsular swelling of the hip joint: this has been an almost constant finding (Fig. 1).

Establishment of diagnosis-The diagnosis in all cases except one has been confirmed either by isolation of the organism or by a positive histological pattern. In the one exceptional case the child was very acutely ill, arthrotomy had been performed within twenty-four hours, with release of a large amount of pus, and penicillin therapy had been begun before operation.

\section{CLINICAL REVIEW}

In the period 1960 to 1967 ninety-six patients with suppurative arthritis have been treated in the Adelaide Children's Hospital. The routine of management outlined above was commenced by the Orthopaedic Department in 1960, and over the ensuing years cases have been referred much earlier with correspondingly better results. The commonest organism responsible was the staphylococcus aureus (Table I).

TABLE I

RESPONSIBLE ORGANISMS

\begin{tabular}{|lcc|}
\hline \multicolumn{1}{|c}{ Organism } & $\begin{array}{c}\text { Number of } \\
\text { joints }\end{array}$ \\
\hline Staphylococcus aureus & $\cdot$ & 57 \\
Streptococcus haemolyticus & & 3 \\
Haemophilus influenzae & $\cdot$ & 2 \\
\hline
\end{tabular}

TABLE II

OLDER CHILDREN

JOINTS AFFECTED (1960-67)

\begin{tabular}{|c|c|}
\hline Joint & Number of cases \\
\hline Hip & 53 \\
\hline Knee . & 19 \\
\hline Elbow . & 7 \\
\hline Shoulder & 4 \\
\hline Ankle . & 4 \\
\hline
\end{tabular}

The series is divided into two groups according to the age of the patients. The incidence of infection in various joints is shown in Table II. Four joints-three knees-were infected after penetrating injuries. All recovered irrespective of the method of treatment. Almost certainly spread by the blood stream from a distant focus of infection was the cause in all the other cases. This type of infection produced more serious damage.

\section{INFANTS}

During this review period there were nine infants whose ages ranged from one week to eleven months with an average of four and a half months. In this group diagnosis is generally made late, so that treatment is inadequate (Table III). In 78 per cent of cases the joint was destroyed (Figs. 2 to 4 ).

During the same period six other infants were referred with a diagnosis of congenital dislocation of the hip. These were cases of suppurative arthritis; they presented with the typical appearance of Tom Smith"s arthritis. Wilkinson"s (1952) remark "the story of these 
hips has been written when the patients reach us" is all too often true. Only with early diagnosis and prompt treatment will it be possible to prevent destruction of these joints.

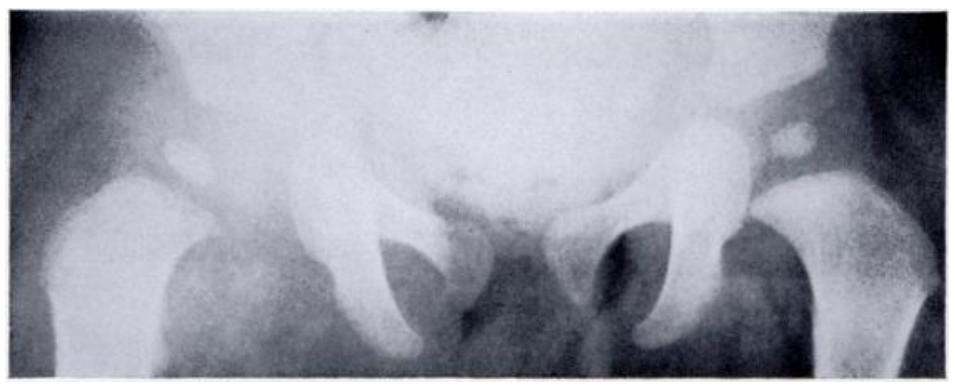

Fig. 2

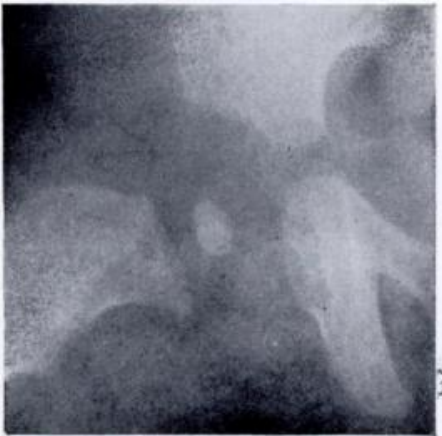

FIG. 3

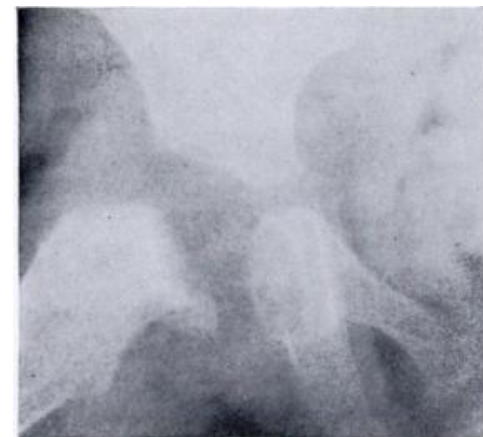

Fig. 4

Suppurative arthritis of the hip in a child of 11 months with a three weeks' history. Figure 2-Subluxation and capsular distension. Figure 3-Two months later: osteomyelitis of the neck of the femur. Figure 4-One month later: destruction of the femoral capital epiphysis.

TABI.E III

TREATMENT AND RESULTS IN INFANTS

\begin{tabular}{|c|c|c|c|c|}
\hline Joint & & Age & Treatment & Result \\
\hline Hip . & & 11 months & Arthrotomy, antibiotics & Pathological dislocation \\
\hline Hip . & & 6 months & Aspiration & Pathological dislocation \\
\hline Hip . & & 6 months & Antibiotics & Pathological dislocation \\
\hline Hip . & & 2 months & Antibiotics & Pathological dislocation \\
\hline Knee & & 5 months & Aspiration & Normal joint \\
\hline Knee & • & 1 month & Aspiration & Destroyed joint \\
\hline Elbow & . & 1 week & Aspiration & Destroyed upper end of ulna \\
\hline Elbow & . & 5 months & Aspiration & Destroyed joint \\
\hline Shoulder & & 5 months & $\begin{array}{l}\text { Arthrotomy, drainage, } \\
\text { plaster, antibiotics }\end{array}$ & Normal joint \\
\hline
\end{tabular}

OLDER CHILDREN

Eighty-seven joints treated between 1960 and 1967 have been reviewed, and the results from the routine treatment outlined have been compared with other methods of treatment VOL. 52 B, No. 3, AUGUST 1970 
which consisted of either aspiration of the joint, drainage of the joint, antibiotics, or a combination of these three treatments.

Table IV indicates that in this period fifty joints with proven suppurative arthritis were treated by the regime outlined: all are clinically and radiologically normal. There were four cases in which the result was unsatisfactory after arthrotomy and the full regime but this was because the operation was eighteen, nineteen, twenty-one and forty-two days after the onset of symptoms, which of course is far too late. Of the thirty-three joints treated by a variety of methods, fifteen were destroyed.

A preliminary review was made in 1965 and since then the Department of Orthopaedic Surgery has treated most cases. It is of significance, therefore, to review the results of treatment in the two periods, 1960 to 1965 and 1965 to 1967.

TABLE IV

Older ChildRen

(Period 1960-67)

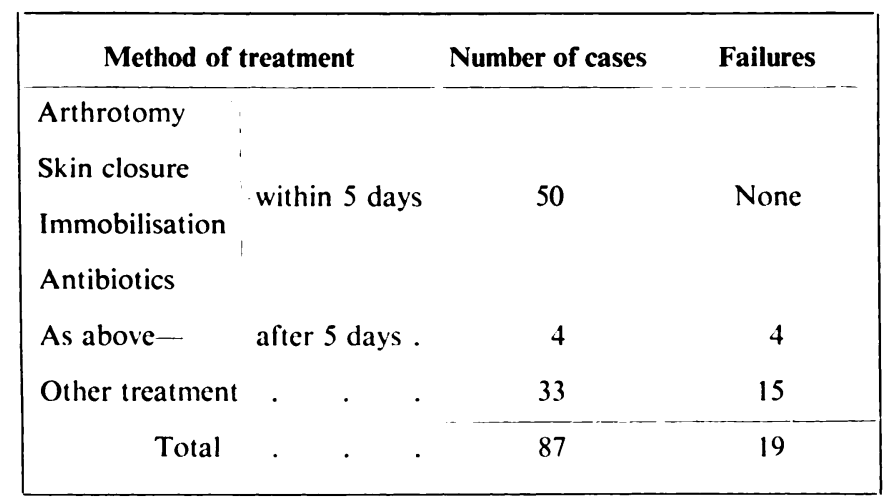

TABLE $V$

Result of Trfatment in TWENTY-Figiht Hips $(1960-65)$

\begin{tabular}{|c|c|c|c|}
\hline Treatment & & Number of cases & Failures \\
\hline Arthrotomy within 5 days & . & 14 & None \\
\hline Arthrotomy after 5 days & . & 4 & 4 \\
\hline Other methods & . & 10 & 5 \\
\hline
\end{tabular}

Period 1960 to 1965-Fifty-four joints were treated. Thirty of these were treated by other methods. Twelve joints were destroyed. Of the failures, five joints were treated by antibiotics only, four by aspiration and antibiotics, and three by open drainage and antibiotics.

The hip is by far the commonest site of affection: during this period twenty-eight infected hips were seen. Sixty-five per cent of the hips treated by methods other than the plan indicated before were destroyed (Table V).

The result of inadequate treatment is all too evident: a six-year-old boy whose hip was drained eighteen days after the clinical onset of suppurative arthritis developed chronic osteomyelitis of the femur with destruction of the femoral head (Figs. 5 and 6). Over the years he has developed increasing shortening of the affected leg (Fig. 7).

Period 1965 to 1967-Only three of thirty-three infected joints were treated by other methods. One hip was treated by incision and drainage, plaster immobilisation for four weeks and 
antibiotics for two weeks. Osteomyelitis of the femoral shaft developed, and after fifteen months full movement had not been regained (Fig. 8). Radiographs showed broadening of the neck of the femur (Fig. 9). The loss of movement was caused by damage to the articular cartilage.
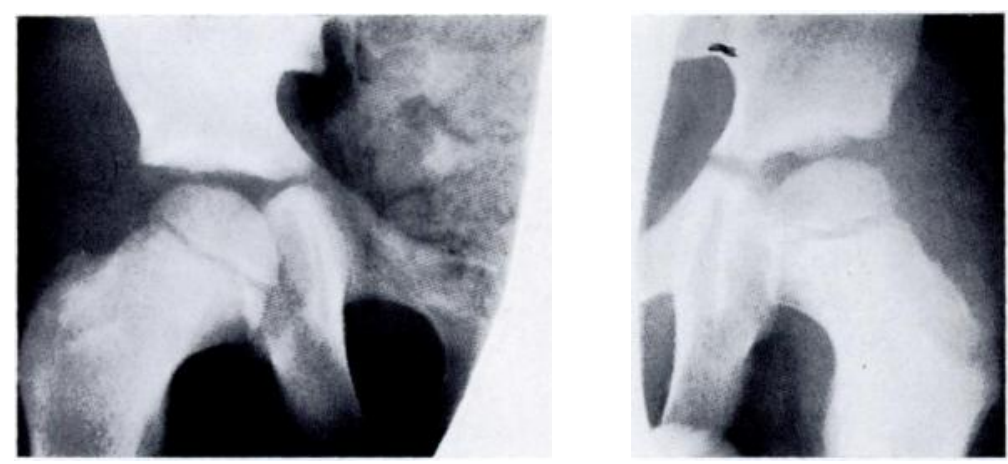

FIG. 5

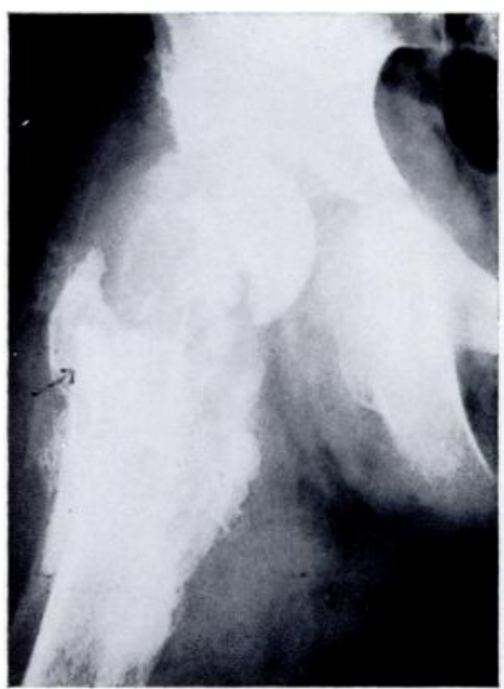

Fig. 6

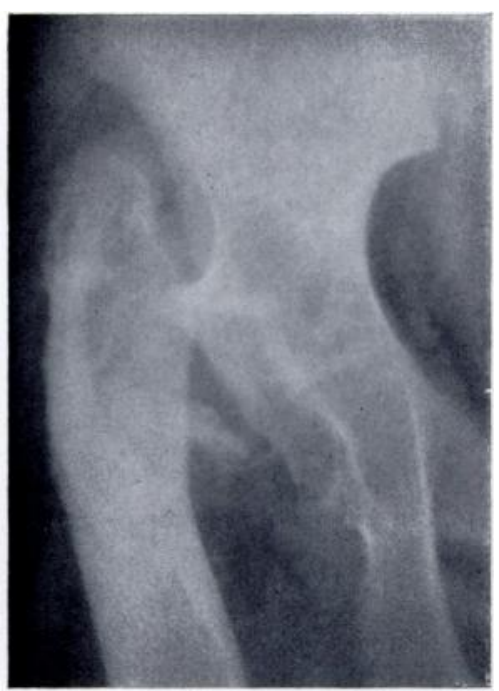

Fig. 7

Suppurative arthritis of the hip in a boy aged 6. Arthrotomy eighteen days after onset of symptoms of suppurative arthritis. Figure 5-Radiograph at the time of operation. Figure 6-Six months later: destruction of the femoral head and chronic osteomyelitis of the femur. Figure 7-Six years later: marked shortening and instability.

Another patient - a baby one month old - had had a painful, swollen knee for one week (Fig. 10). The knee was treated by aspiration only: there was progressive destruction of the lateral femoral condyle (Fig. 11).

Thirdly, an infected elbow was treated by arthrotomy, wound drainage and antibiotics. The result was damage to the lower end of the humerus with permanent loss of movement of the elbow joint (Fig. 12). This failure emphasises that superficial joints should be treated the same way as the deeper ones.

The thirty joints treated by the full regime have returned to full function.

COMPLICATIONS

Arthrotomy hased on incorrect diagnosis-One price of success with early operation has been eleven unnecessary arthrotomies (Table VI). With experience this is happening less: in the 


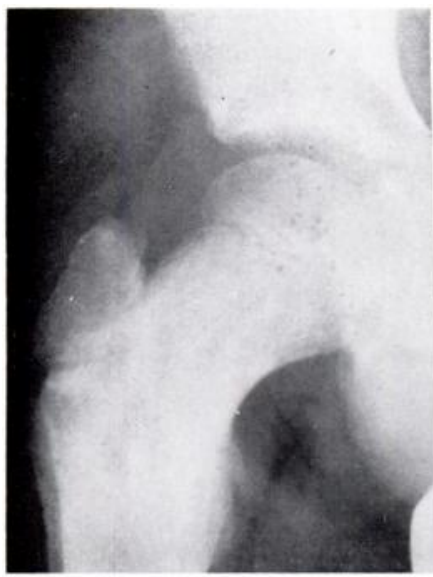

FIG. 8

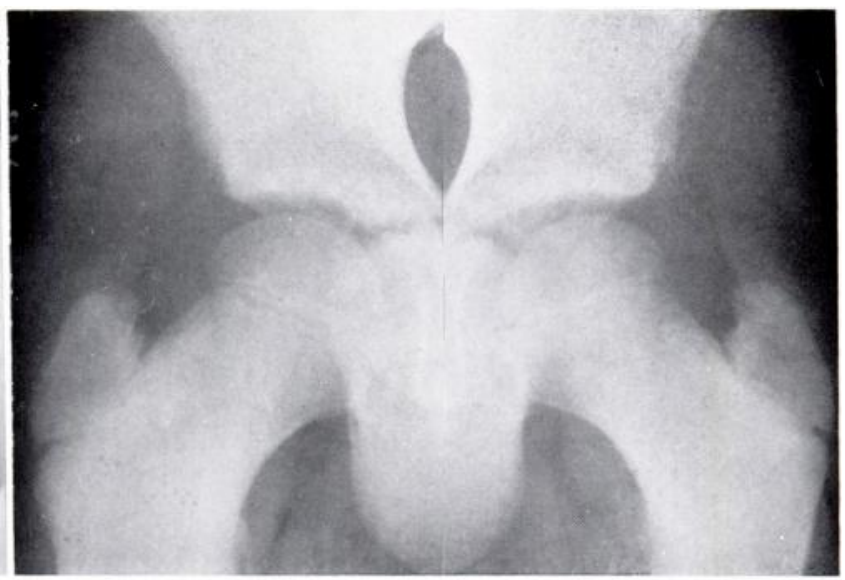

FIG. 9

Suppurative arthritis of the hip treated by arthrotomy and limited antibiotics. Figure 8-Evidence of osteomyelitis of the upper femoral shaft. Figure 9-Residual thickening of the neck of the femur. Left hip shown for comparison.

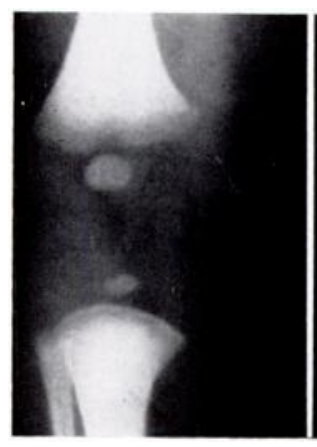

Fig. 10

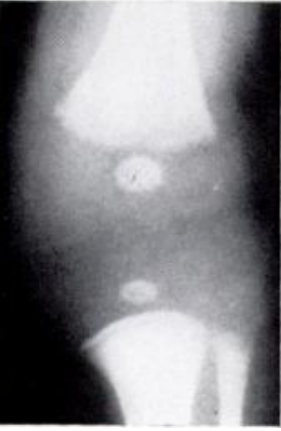

of the

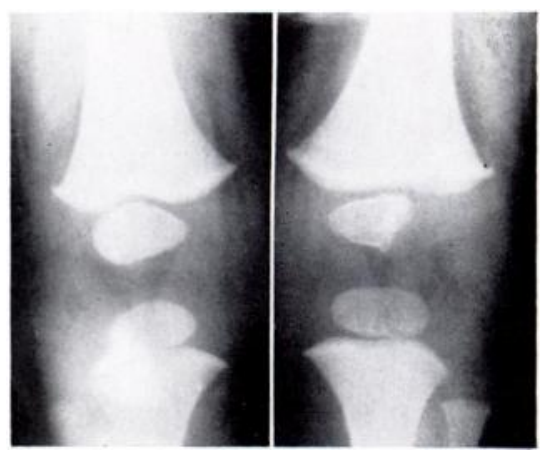

Fig. 11

Suppurative arthritis of the knee in a child aged 1 month. History of swelling and pain for one week. Figure 10-Radiograph at the time of admission. Figure 11-Destruction of the lateral femoral condyle.

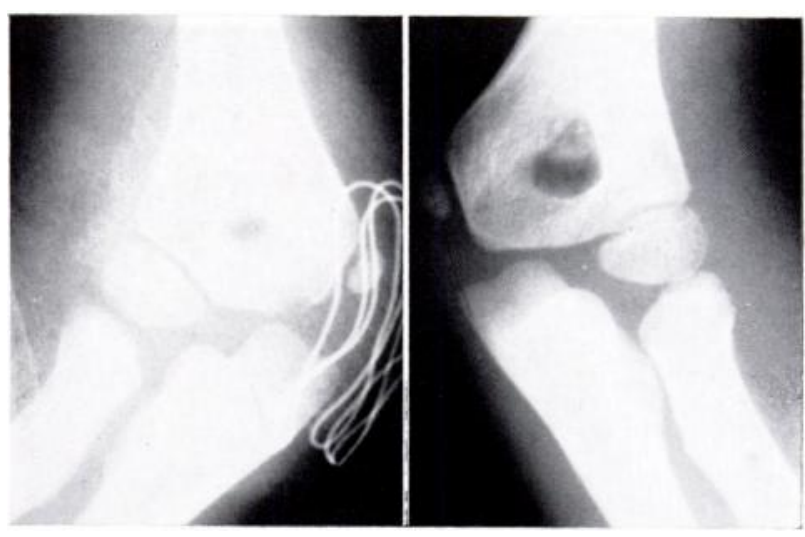

FIG. 12

Suppurative arthritis of the elbow treated by arthrotomy with wound drainage and antibiotics. There is damage to the articular surface of the humerus. 
period 1965 to 1967 only one of seven hips was being subjected to unnecessary arthrotomy. Nevertheless, it is considered preferable to submit a child to an unnecessary arthrotomy than to run the risk of allowing a joint to be destroyed by delay. There has been no ill-effect from these arthrotomies.

TABLE VI

Unneclessary Arthrotomy: Correct Diaginosis

\begin{tabular}{|c|c|c|}
\hline \multirow{2}{*}{ Diagnosis } & \multicolumn{2}{|c|}{ Number of cases } \\
\hline & $1960-65$ & $1965-67$ \\
\hline Rheumatoid arthritis & 2 & 1 \\
\hline Traumatic synovitis & 3 & 3 \\
\hline Osteomyelitis of the greater trochanter & 1 & 1 \\
\hline
\end{tabular}

Rate of misdiagnosis: $1960-65: 1$ in $5.1965-67: 1$ in 7.

Coxa magna-This is a complication of suppurative arthritis of the hip only. There have been six cases, but the joints have a full range of painless movement (Figs. 13 and 14).

Brodie's abscess-There have been three cases: all settled satisfactorily on the full regime and the patients regained normal function of the joints.

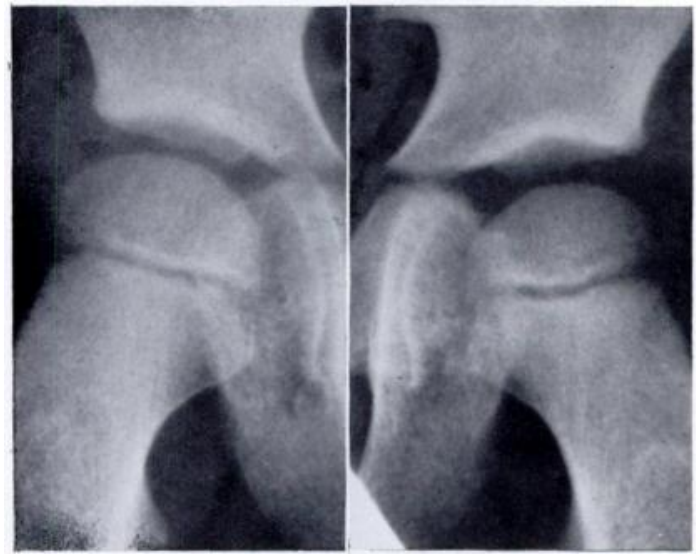

Fig. 13

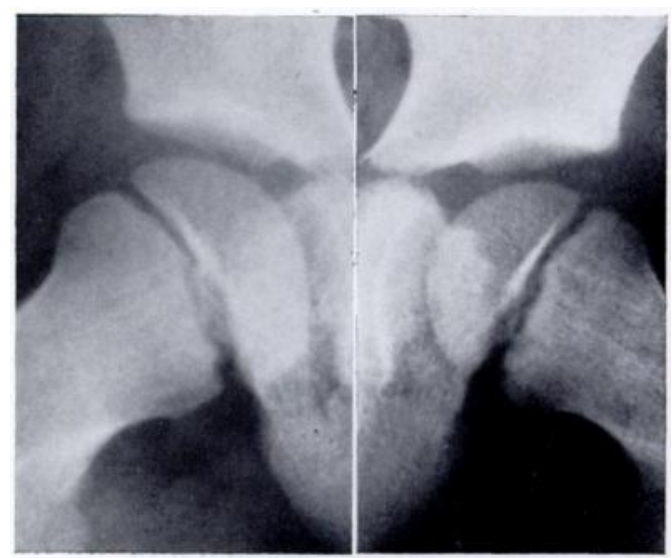

FIG. 14

Antero-posterior and lateral radiographs showing coxa magna.

\section{CONCLUSIONS}

1. A regime of treatment for acute suppurative arthritis in childhood has been proposed. This consists of: urgent arthrotomy of the affected joint, if possible within five days; skin closure without drainage; antibiotics; and immobilisation of the joint for six weeks.

2. Fifty hips have been treated by this regime: all are clinically and radiologically normal The failure to achieve these results with other forms of treatment is due to delay in diagnosis, inadequate drainage together with lack of immobilisation of the affected joint, and inadequate treatment with antibiotics.

3. Early diagnosis determines the ultimate prognosis. It is suggested that in doubtful cases exploratory arthrotomy is indicated. Eleven hips were found to have some other cause for the signs and symptoms, but the children have suffered no ill effects from the arthrotomy.

4. Diagnostic aspiration is an unsatisfactory method, especially in the case of the hip, and should be avoided. Incision is preferable. 
5. Acute suppurative arthritis of infancy is a serious condition. Diagnosis is difficult and is often delayed, so that the affected joint may be destroyed. In this small series of nine, seven affected joints were destroyed.

I wish to thank the Medical Superintendent, Dr W. T. McCoy, and my surgical colleagues of the Adelaide Children's Hospital for allowing me to review these cases. I am greatly indebted to the late Lansell Bonnin. It was under his guidance that this regime of management was commenced. I much appreciate the help given by Mr Ray Boyd, Clinical Photographer at the Adelaide Children`s Hospital.

\section{REFERENCES}

Aberdeen, J. D. (1965): The Problems of Osteomyelitis in Childhood. Medical Journal of Australia, $2,357$.

Curtiss, P. H., Jun., and Klein, L. (1963): Destruction of Articular Cartilage in Septic Arthritis. I. In Vitro Studies. Journal of Bone and Joint Surgery, 45-A, 797.

Curtiss, P. H., Jun., and Klein, L. (1965): Destruction of Articular Cartilage in Septic Arthritis. II. In Viro Studies. Journal of Bone and Joint Surgery, 47-A, 1595.

Eyre-Brook, A. L. (1960): Septic Arthritis of the Hip and Osteomyelitis of the Upper End of the Femur in Infants. Journal of Bone and Joint Surgery, 42-B, 11.

Heberling, J. A. (1941): A Review of Two Hundred and One Cases of Suppurative Arthritis. Journal of Bone and Joint Surgery, 23, 917.

INGE, G. A. L., and Liebolt, F. L. (1935): The Treatment of Acute Suppurative Arthritis. Surgery, G.'mecology and Obstetrics, 60, 86.

MCFarland, B. (1961): Suppurative Arthritis of the Hip in Infancy. Journal of Bome and Joint Surgery, 43-B, 191.

Obletz, B. E. (1960): Acute Suppurative Arthritis of the Hip in the Neonatal Period. Journal of Bone and Joint Surgery, 42-A, 23.

Samilson, R. L., Bersani, F. A., and Watkins, M. B. (1958a): Acute Suppurative Arthritis in Infants and Children. Pediatrics, 21, 798.

Samilson, R. L., Bersani, F. A., and Watkins, M. B. (1958b): Acute Suppurative Arthritis in Infants and Children. Journal of Bone and Joint Surgery, 40-A, 978.

Wainwright, D. (1961): Septic Arthritis of the Hip in Infants. Journal of Bone and Joint Surgery, 43-A, 295. 